\section{Category}

Synthesis of

Heterocycles

\section{Key words}

azlactones

asymmetric

catalysis

peptides

quaternary amino acids

\title{
Access to Quaternary Amino Acids via Dynamic Kinetic Resolution of Azlactones
}
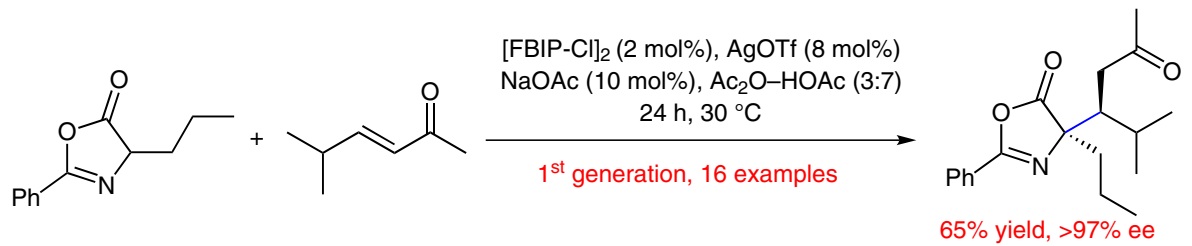<smiles>CCCC(NC(=O)c1ccccc1)C(=O)O</smiles>

[FBIP-Cl] $]_{2}(2 \mathrm{~mol} \%), \operatorname{AgOTf}(8 \mathrm{~mol} \%)$ $\mathrm{NaOAc}(10 \mathrm{~mol} \%), \mathrm{Ac}_{2} \mathrm{O}-\mathrm{AcOH}(3: 7)$

$P$

$2^{\text {nd }}$ generation, 16 examples

[FBIP-Cl] 2 (2 mol\%), AgOTf (12 mol\%)<smiles>CCCC(N)C(=O)O</smiles>
NaOAc (25 mol\%), THF-toluene (10:1),<smiles>CCC[C@@]1([C@H](CC(C)=O)C(C)C)N=C(c2ccccc2)OC1=O</smiles>

$3^{\text {rd }}$ generation, 24 examples

Significance: Due to their ability to both provide greater stability against degradation and to restrict conformational flexibility of peptides, quaternary $\alpha$-amino acids are an important compound class. Azlactones have been extensively used for the asymmetric assembly of these quaternary centers taking advantage of the tendency for enolization at the C4-position owing to the aromatic character of the enol tautomer. The current study provides the first report on the 1,4-addition of azlactones to enones mediated by a readily accessible (four steps from ferrocene) planar-chiral ferrocene bisimidazoline bispalladacycle (FBIP). Three protocols are developed including enabling the intermediate azlactone to be assembled in situ from a racemic amino acid. High levels of enantiocontrol are obtained for the reactions and the range of synthetic utility of the products is demonstrated in the synthesis of amino acids, proline derivatives, cyclic dipeptides and (pyro)glutamic acids.
Comment: In all cases of the Michael addition of azlactones to enones examined, the products were formed in diastereomerically pure form. The optimal C2-substituent was phenyl and the enantioselectivity of the reaction increased with the steric bulk of the C4-substituent. Key to the reaction is addition of both a silver salt (AgOTf), and sodium acetate using a solvent system of acetic acid-acetic anhydride. The ability to recycle the catalyst system with minimal loss of performance over seven cycles was demonstrated. A system to utilize unprotected amino acids was also described. In this case, significant optimization was required to minimize competing formation of the regioisomeric $\mathrm{C} 2$-addition product (generated as a racemic mixture). Detailed mechanistic studies suggest the operation of a bimetallic activation pathway. 